\title{
Hacia el reconocimiento de los derechos políticos de los pueblos originarios: El modelo de cogestión en Isla de Pascua
}

Pablo Andueza G.'

\section{RESUMEN}

El Estado chileno monopoliza el campo de acción política acerca de los territorios indígenas en nombre de la integridad territorial. Mientras tanto, el pluralismo político parece estar instalándose en Isla de Pascua. El objetivo de este artículo es explicar el proceso de la estrategia de "rapanuización" en la isla, y cómo la administración compartida de Isla de Pascua entre el Gobierno chileno y el pueblo rapanui va imponiéndose en los procedimientos políticos así como en la ley chilena substantiva.

\begin{abstract}
The chilean State monopolizes the field of political action in the name of territorial integrity. Whereas political pluralism seems to take place in Easter Island. The aim of this paper is to explain the process of "rapanuization" strategy in the island and how the shared administration of Easter Island between the chilean Government and rapanui people imposes upon political procedures as well as chilean substantive law.
\end{abstract}

1 Departamento de Antropología de la Universidad de Chile y Escuela de Psicología, Universidad de Valparaíso. Email: pandueza@entelchile.net

2 En efecto, el principal efecto jurídico de la declaración de una deterninada zona del país como "área de desarrollo indígena" consiste en que la Corporación Nacional de Desarrollo Indígena (CONADI) podrá coordinar en ella planes, programas y proyectos en forma armoniosa. No obstante, una regla importante para la isla que sobrevivió del proyecto original es la consagrada en el articulo 35 del texto definitivo de la Ley Indígena: en las zonas silvestres protegidas ubicadas en estas áreas se considerará la participación de las comunidades ahí existentes. Los rapanui promueven la declaración de la isla como "área de desarrollo indígena" pues les permitiría incidir más activamente en la administración del Parque Nacional Rapa Nui que abarca casi la mitad de su territorio.

\section{Introducción. La gestión de territorios indígenas en Chile}

El Estado chileno no reconoce a los pueblos originarios el derecho de autodeterminación sobre los territorios que éstos han ocupado desde hace siglos; por el contrario, reafirma sistemáticamente el principio de la integridad nacional: su territorio debe ser gobernado monopólicamente por las instituciones oficiales de la nación chilena.

La rigidez de la posición chilena quedó en evidencia a propósito de la discusión parlamentaria de la Ley Indígena de 1993. Los intentos del ejecutivo por promover formas autogestionadas de manejo de zonas indígenas, denominadas inicialmente "territorios de desarrollo indígena", quedaron diluidos en las inocuas "áreas de desarrollo indígena" aprobadas en definitiva en la ley, las que no pretenden otra cosa que constituirse en una herramienta para focalizar los planes y programas gubernamentales hacia los habitantes indígenas (Barrientos 2000). ${ }^{2}$

En síntesis, en Chile los pueblos originarios no intervienen significativamente en la gestión de sus territorios. Invocando el principio de la integridad territorial, el Estado chileno controla monopólicamente el campo de acción política. De ahí que la experiencia de cogestión del territorio de Rapa Nui, que es el objeto del presente trabajo, pueda transformarse en un interesante precedente en la lucha de los pueblos indígenas de Chile en favor del reconocimiento de derechos políticos.

\section{Estado y colonización en Isla de Pascua}

Hasta el año 1888 , en que Chile efectúa la anexión del territorio insular, Rapa Nui era jurídicamente un pequeño Estado independiente con un gobierno interior autónomo bajo control compartido entre los 
propios rapanui y los administradores de la estancia ovejera; de hecho era además un protectorado francés (Mc Call, 1996). Con la anexión a Chile la isla pierde su autonomía política y sus habitantes originarios son progresivamente privados de sus derechos políticos fundamentales. Los rapanui, por décadas, no solamente estuvieron marginados de la gestión política y económica de su territorio, sino además no gozaron siquiera de la calidad de ciudadanos de la República, como acontecía con la mayoría de los indígenas del país desde la misma constitución del Estado chileno.

Rapa Nui fue gobernada a lo largo de la mayor parte del siglo XX por los agentes colonizadores vinculados a la compañía ovejera que explotaba económicamente la isla y a la Armada de Chile que representó por mucho tiempo al Estado chileno. ${ }^{3} \mathrm{La}$ institución naval asumió el completo control de la isla entre 1953 y 1965 , momento en el cual este territorio se incorpora en plena forma a la administración del Estado de Chile. ${ }^{4}$

Veamos brevemente las características fundamentales de cada período:

Período de control por la compañía ovejera (19031953)

Aún cuando autoridades y funcionarios civiles y navales chilenos la visitaban periódicamente, el control político de la isla estaba claramente en manos de los administradores de las compañías ganaderas (Porteous 1993). La compañía chileno-escocesa Williamson Balfour dominó autoritariamente la isla durante la primera mitad del siglo XX a la manera que Porteous llamó "a tropical version of the 18thcentury Scottish Highlands" (Porteous 1993: 226).

Período de control por la Armada chilena (19531965)

La forma autoritaria y colonial de gobierno isleño

3 Hasta 1953, fecha en que la Armada chilena asume directamente el control político de la isla, Rapa Nui fue entregada en arrendamiento a una compañía transnacional de explotación ovejera. Por tanto, durante la primera parte del siglo XX la misión naval fue intermitente y más bien ligada a tareas jurisdiccionales y de abastecimiento (Mc Call 1996).

4 La ley 16.441 de 1966, creó instituciones político-judiciales tales como la Municipalidad de Isla de Pascua y el Juzgado de Letras, las que asumirían en lo sucesivo el control político de la isla. no cambia significativamente con el traspaso de la isla a manos de la armada chilena (Grifferos 1997 y 1997a). Sin perjuicio del esfuerzo moderador de la institución naval frente al despotismo de la Compañía, puesto en evidencia entre otros por McCall (1996), lo cierto es que la marginación política y cultural de los rapanui no se mejora en este periodo al punto que motiva, a mediados de los años ' 60 , la revuelta rapanui liderada por el profesor Alfonso Rapu.

\section{Período de "chilenización" (1965-1990)}

La rebelión rapanui de 1965, que reclamaba el reconocimiento de su condición de ciudadanos chilenos frente al despotismo reinante en la isla, y la respuesta "chilenizadora" del gobierno de orientación social-cristiana de la época, marca un cambio sustantivo del estado de cosas en la isla (McCall 1996, Porteous 1993). Rapa Nui se incorpora territorialmente a la administración del Estado chileno ampliando sustancialmente sus ámbitos de acción (jurisdiccional, servicios públicos, etc.), lo que viene facilitado evidentemente por el establecimiento de servicios aéreos regulares entre la isla y el continente. Sus habitantes adquieren durante este período la ciudadanía chilena.

\section{La "rapanuización" de Isla de Pascua}

El fin de la colonización se encuentra aún pendiente pero parece ser una hecho que, en palabras de McCall, "a medida que la cultura diaria de los rapanui se vuelve más chilena, es fácil ver cómo la cultura pública se tornará más rapanui" (1998: 168). Efectivamente, desde hace décadas, el pueblo rapanui viene reapropiándose de los espacios políticos isleños que habían estado históricamente controlados por los colonizadores, lo que se hace más evidente en los últimos diez años (Andueza 2000). La "rapanuización" es una estrategia, tal como Pierre Bourdieu (1991) ha concebido esta noción, es decir, una concertación de prácticas producida por los rapanui en el marco de condiciones sociales e históricas concretas, la que sin ser necesariamente racional favorece la posición rapanui en la política local.

$\mathrm{Al}$ interior de las nuevas instituciones públicas creadas durante la década del ' 60 surgiría el germen del proceso de "rapanuización" isleño que se hace evidente con la transición a la democracia en la década 
del '90. La Municipalidad de Isla de Pascua, por ejemplo, ha permanecido en manos rapanui desde su constitución. La mayoría de los regidores o concejales locales han sido rapanui. Durante el gobierno militar se designó por primera vez a un rapanui como Gobernador de la isla, transformándose en un precedente respetado por los gobiernos chilenos hasta hoy día.

La "rapanuización" de la Isla de Pascua se ha hecho más palmaria con la llegada de la democracia a tal punto que parece hoy un proceso difícilmente reversible. A partir de los gobiernos democráticos ha comenzado a surgir en la isla una nueva visión del desarrollo y la gestión del territorio insular. Las ideas centralizadoras e impositivas de gestión comienzan a dar paso a un proceso de gestión negociada, que ha incluso incluido el tema candente de la tenencia de la tierra. Esta modalidad de administración negociada la denominamos cogestión: las decisiones que puedan afectar a la isla son tomadas en conjunto con las autoridades locales de origen rapanui, aceptando por esta vía un progresivo proceso de "rapanuización" moderada del territorio insular, aunque siempre bajo el control estatal.

Para situar debidamente en su contexto el nuevo modelo de gestión de Rapa Nui es necesario tener una idea aproximada del mapa político isleño reciente.

\section{Fotografía política de Rapa Nui actual ${ }^{5}$}

a) La primera gran tensión política en Rapa Nui es, evidentemente, la existente en la relación entre el pueblo rapanui (habitantes originarios de la isla) y el Estado chileno que ocupa la isla, directamente o a través de terceras partes, desde hace más de un siglo. Los rapanui pueden aceptar --como sus antepasados recientes-- la soberanía chilena pero rechazan la usurpación de sus tierras por parte del fisco chileno ${ }^{6}$ y la gestión etnochilena del territorio

5 Esta fotografía política isleña fue "tomada" durante 1995, año en que este profesional colaboró con la Municipalidad de Isla de Pascua y el Gobiemo Regional de Valparaíso en el tema de la planificación local, en el marco del Programa de Desarrollo Regional (PAREDE) auspiciado por el Programa de las Naciones Unidas para el Desarrollo (PNUD).

6 En 1933, invocando el principio de adquisición de terra nullitus, el fisco consolida legalmente la propiedad de las tierras de Rapa Nui registrándolas a su nombre en el Conservador de Bienes Raíces de Valparaíso. insular. Por su parte, el Estado chileno y sus agentes han visto la ocupación y el control político de Rapa Nui como un fenómeno natural y no han reparado en su significación colonialista.

Una buena síntesis de la tensión étnica se expresa en la manera cómo chilenos y rapanui han visualizado el desarrollo de Rapa Nui. Mientras para el Estado de Chile el desarrollo ha tenido que ver con la materialización de los planes y estrategias nacionales en el territorio insular, de características peculiares (fin del aislamiento, mejoramiento de los servicios públicos, desarrollo productivo, etc.), para la población rapanui el desarrollo tiene que ver con la recuperación de la tenencia de las tierras para la etnia y el manejo autónomo de su territorio (Andueza 2000).

La oposición de intereses entre rapanui y chilenos inherente a su contexto colonial subyace en la mayor parte de los conflictos que han sacudido a la isla a lo largo del siglo XX (Andueza 2000, Castro 1996, Grifferos 1997 y 1997a). Mostrándose abiertamente crítica frente a la etnología tradicional de Rapa Nui y, como asimismo frente al discurso chileno preponderante, que han explicado con demasiada ligereza el ambiente belicoso isleño a la personalidad de los habitantes originarios ${ }^{7}$, la historiografía actual parece centrarse cada vez más en la perspectiva rapanui revelando el contexto colonial de la isla y la lucha indígena por su identidad (Grifferos 1997 y 1997a).

Aparentemente, no obstante, la tensión interétnica se ha modelado durante los últimos años gracias al cambio de actitud experimentado por el Estado de Chile respecto a la isla y al pueblo rapanui. Desde el punto de visto simbólico, el Estado parece resuelto a reconocer validez y legitimidad a la posición rapanui; desde el punto de vista político, parece conformarse con la "rapanuización" de la isla y la devolución progresiva de tierras isleñas (no comprometidas arqueológicamente), aunque asegurándose la soberanía chilena sobre el territorio.

\footnotetext{
7 Transcribamos a Métraux: "Numerous conflicts have arisen between the natives and the company (Williamson Balfour). Stealing has been one of the chief sources of trouble, but many others difficulties have come from the turbulent spirits of natives and their easily excited imagination. Easter islanders are apt to believe the most unfounded rumors, and easily convinced that others nourish bad intentions toward them" (1971: 47-48).
} 
La nueva política de estado, que como puede advertirse, facilita enormemente una agenda común chileno-rapanui, es pionera en el contexto del país $\mathrm{y}$, como lo señalamos anteriormente, puede constituirse en un auspicioso precedente para otras regiones de Chile de alta densidad indígena.

b) Es necesario advertir, sin embargo, por lo menos en el caso Rapa Nui, que la población chilena que convive con la población indígena puede verse amenazada por el cambio gubernamental. Una parte significativa de la comunidad chilena residente en la isla rechaza la discriminación positiva en favor de los rapanui, especialmente aquella que le imposibilita legalmente a acceder a la propiedad de la tierra local. Este grupo aboga por la (re)chilenización y el pleno cumplimiento de las leyes nacionales en la isla.

c) Para hacer aún más complejo el tema, es necesario recordar que la oposición chileno-rapanui no es la única fuente de tensión en la isla. Al interior de la misma comunidad rapanui existen importantes diferencias.

Aunque todos los rapanui están a favor tanto de la rapanuización de la política isleña como en que las tierras de Rapa Nui son para sus habitantes originarios, se ha discrepado sobre el régimen jurídico de tenencia de tierras, lo que en parte explica la división del Consejo de Ancianos. El Consejo de Ancianos $N^{\circ} 1$ (ver cuadro 1), liderado por don Alberto Hotus, ha defendido la idea de proteger las tierras isleñas no solamente frente a agentes foráneos sino frente a agentes de la propia comunidad local que podrían entrar a concentrar la propiedad de la tierra. Ante estas amenazas, la propuesta ha sido un régimen socializado de tenencia rapanui de la tierra, tal como lo establece la Ley Indígena. El Consejo de Ancianos $\mathrm{N}^{\circ} 2$ ha defendido, como el primer Consejo, la tenencia rapanui de la tierra, pero bajo la modalidad liberal o capitalista, lo que le ha hecho tomar distancia respecto de la Ley Indígena chilena.

\section{Las estrategias y el poder de los actores}

El Estado decide modificar su actitud frente a la conflictiva cuestión rapanui encomendando en el subsecretario del Interior, Belisario Velasco, la tarea de interlocutor permanente con la comunidad local, fundamentalmente en el contexto de la nueva legislación indígena. Al mismo tiempo, decide hacer cumplir las promesas incumplidas de Chile en orden a restituir progresivamente las tierras isleñas a sus habitantes tradicionales respetando el tiempo y los requerimientos locales. ${ }^{8}$

\section{Cuadro 1. Mapa político de la isla en 1995}

\begin{tabular}{|l|l|l|l|}
\hline ACTORES & PRINCIPIO & ESTRATEGIAS & INSTRUMENTOS \\
\hline $\begin{array}{l}\text { Consejo de Ancianos } \\
\mathrm{N}^{\circ} 1\end{array}$ & "Rapanuización tradicional" & $\begin{array}{l}\text { 1. Restitución progresiva de las } \\
\text { tierras a rapanuis } \\
\text { 2. Régimen protegido de tenencia } \\
\text { 3. "Empoderamiento" rapanui }\end{array}$ & $\begin{array}{l}\text { Ley Indígena } \\
\text { Negociación con Gobierno } \\
\text { de la Concertación }\end{array}$ \\
\hline $\begin{array}{l}\text { Consejo de Ancianos } \\
N^{\circ} 2\end{array}$ & $\begin{array}{l}\text { "Rapanuización } \\
\text { capitalista" }\end{array}$ & $\begin{array}{l}\text { 1. Restitución de las tierras a apanuis } \\
\text { rapey especial para Rapa Nui } \\
\text { 2. Régimen liberal de tenencia } \\
\text { 3. "Empoderamiento" rapanui }\end{array}$ & $\begin{array}{l}\text { Rebelión contra gobiernode } \\
\text { Chile }\end{array}$ \\
\hline $\begin{array}{l}\text { Gobierno de Chile } \\
\text { "Rapanuización controlada" }\end{array}$ & $\begin{array}{l}\text { 1. Restitución parcial poder políti- } \\
\text { co y de tierras a rapanuis }\end{array}$ & $\begin{array}{l}\text { Ley Indígena } \\
\text { Negociación con rapanuis }\end{array}$ \\
\hline $\begin{array}{l}\text { Chilenos residentes } \\
\text { de oposición }\end{array}$ & "Chilenización" & $\begin{array}{l}\text { 1. Aplicación de las leyes nacio- } \\
\text { nales en materia de tierras }\end{array}$ & $\begin{array}{l}\text { Leyes nacionales y Ley } \\
\text { Especial para Isla de Pascua } \\
\text { Criticismo frente a Gobierno }\end{array}$ \\
\hline
\end{tabular}

8 La actitud flexible del Estado chileno la explicamos, entre otros factores particulares de Rapa Nui, por lo siguiente: a) en la isla no existen comprometidos intereses económicos dominantes nacionales o internacionales como sucede en el sur de
Chile; b) el territorio de la isla viene acotado geográficamente por el océano y, por tanto, no es potencialmente "ampliable" como sucede con otros territorios indígenas. 
Para el año 1995, como decíamos más arriba, el pueblo rapanui aparece dividido en dos grupos: el Consejo de Ancianos $\mathrm{N}^{\circ} 1$ y el Consejo de Ancianos $\mathrm{N}^{\circ}$ 2. Sabemos que ambos grupos han estado unidos en aspectos sustanciales como es lo que hemos llamado la "rapanuización" de la isla. Este ideario común pascuense de larga data comprende algunos aspectos como los siguientes:

- la tenencia rapanui de la tierra

- el aumento sostenido del poder de la comunidad isleña en asuntos que afecten a la isla

- la protección de la cultura rapanui (notablemente la lengua)

Las diferencias se han centrado principalmente en el régimen legal de tenencia de la tierra que el Estado deberá transferir a los habitantes de origen rapanui. Repitamos: mientras el Consejo de Ancianos $N^{\circ} 1$ ha propiciado la Ley Indígena y el marco regulatorio socializado de tenencia de la tierra, el Consejo $\mathrm{N}^{\circ} 2$ ha favorecido el retiro de la etnia rapanui de la ley indígena y la dictación, en su reemplazo, de una nueva ley especial para la isla que asegure un régimen liberal de tenencia de tierras. Detrás de ambas posiciones, se esconden ideas dis- tintas del desarrollo: mientras para el Consejo de Ancianos $\mathrm{N}^{\circ} 1$ el desarrollo debe abarcar a todos sus miembros e ir en consonancia con la cultura tradicional rapanui, para el Consejo $\mathrm{N}^{\circ} 2$ el desarrollo tiene que dar cuenta más bien de los requerimientos capitalistas. $^{9}$

Las estrategias de ambos grupos han apuntado al Estado de Chile pero con matices diferentes (ver Cuadro 2). El Consejo de Ancianos $\mathrm{N}^{\circ} 1$ ha forjado sistemáticamente una alianza estratégica con los gobiernos de la Concertación a través de negociaciones discretas encaminadas a la plena vigencia de la Ley Indígena. Al mismo tiempo, ha propendido a alianzas con la comunidad internacional, en esta época extremadamente sensible frente a la cuestión indígena. El Consejo de Ancianos $\mathrm{N}^{\circ} 2$, en cambio, ha recurrido a tácticas de rebelión de corte más efectista, centradas en la denuncia hacia el Estado colonizador, tales como la ocupación de la Iglesia local, el cobro ilegal de derechos de ingreso al parque nacional, la emisión de radio clandestina en lengua rapanui, por mencionar las más significativas. Esta actitud hostil hacia el Estado chileno, ha mantenido al grupo más bien aislado del continente, sin apoyo de su natural aliado, la derecha continental. ${ }^{10}$

\section{Cuadro 2. Actores rapanui y poder en 1995}

\begin{tabular}{|l|l|l|l|}
\hline \multicolumn{1}{|c|}{ ACTORES } & OBJETIVOS & INSTRUMENTOS & PODER \\
\hline $\begin{array}{l}\text { Consejo de Ancianos } \\
\mathrm{N}^{\circ} 1\end{array}$ & $\begin{array}{l}\text { Alianza con Gobierno } \\
\text { de la Concertación }\end{array}$ & $\begin{array}{l}\text { Negociación } \\
\text { Defensa Ley Indígena }\end{array}$ & $\begin{array}{l}\text { Apoyo de la mayoría } \\
\text { de la comunidad } \\
\text { rapanui }(+)^{11} \\
\text { Contactos privilegiados en } \\
\text { Chile y en el exterior }(+)\end{array}$ \\
\hline & Alianza internacional & $\begin{array}{l}\text { Participación en foros } \\
\text { Contactos con otros } \\
\text { pueblos polinésicos }\end{array}$ & $\begin{array}{l}\text { Rebelión anticolonizadora } \\
\text { Ley especial }\end{array}$ \\
\hline $\begin{array}{l}\text { Consejo de Ancianos } \\
N^{\circ} 2\end{array}$ & Incremento de poder & $\begin{array}{l}\text { Temas sensibles }(+) \\
\text { Escaso contacto } \\
\text { exterior }(-)\end{array}$ \\
\hline
\end{tabular}

9 A una conclusión similar llega Susana Rochna (1996). Adelanta la tesis que el Consejo de Ancianos $\mathrm{N}^{\circ} 2$ se nutre del apoyo de la mayor parte de los comerciantes y empresarios turísticos isleños, en el pasado fuertemente vinculados al régimen militar de Pinochet.

10 Es interesante destacar que, aparentemente, muchos de los conflictos entre ambos grupos han sido mediados por miembros de la familia Edmunds, que se ha caracterizado por proveer autoridades al interior de la isla. Es el caso del
Gobernador de Isla de Pascua Jocobo Hey y del actual alcalde de Isla de Pascua Pedro Edmunds. Ambos mantenían en esa época buenos contactos con ambos Consejos

11 En elección de abril de 1999 , el presidente del Consejo $\mathrm{N}^{\circ} 1$ Alberto Hotus obtuvo 407 preferencias, en tanto que Matías Riroroko del Consejo $\mathrm{N}^{\circ} 2$ alcanzó 332 sufragios. El año 2000 , en la designación del representante rapanui a la CONADI, nuevamente vence Hotus. 


\section{El modelo de cogestión de Rapa Nui}

\section{Consagración legal}

El modelo de cogestión de Isla de Pascua, y la Comisión de Desarrollo de Isla de Pascua (CDIP) que la institucionaliza, es el resultado de un largo proceso de negociación entre el Estado chileno y el pueblo rapanui. En definitiva, se le incorpora a la Ley Indígena 19.253, publicada en octubre de 1993, y al decreto 394, de noviembre del mismo año, que regula la CDIP, a pesar de la oposición tenaz de una parte de la población rapanui. El modelo pascuense debe situarse, en consecuencia, en el marco de la protección nacional e internacional de los pueblos indígenas.

\section{Derechos colectivos}

Conjuntamente con reconocerse en favor del pueblo rapanui derechos culturales equivalentes a los otros pueblos indígenas (de poseer un sistema de vida y una organización histórica, idioma, formas de trabajo y manifestaciones culturales autóctonas), la Ley Indígena efectúa dos importantes concesiones a Rapa Nui:

- Se reconoce el derecho de incidir significativamente en las más importantes decisiones que pueden afectar a la isla (relacionadas, por ejemplo, con la entrega de tierras, la planificación y la gestión del territorio) que son asumidas por la CDIP. ${ }^{12}$

- Se establece un procedimiento en manos de la CDIP destinado claramente a favorecer la ampliación de las tierras a los habitantes originarios.

\section{Rapanuización}

La "rapanuización" de Isla de Pascua se profundiza en la nueva institucionalidad indígena en tres direcciones:

12 La CDIP tiene las siguientes principales facultades: a) substituir a la antigua Comisión de Radicaciones creada por el Decreto Ley 2.885, que dicen relación con el traspaso de tierras a los isleños; b) formular y ejecutar programas, proyectos y planes de desarrollo para la isla; $\mathrm{y}$ c) colaborar en la administración del territorio local, el parque nacional por ejemplo.
Se aprecia un proceso de descentralización de la administración insular. La gestión chilenizadora, portadora por definición de una escala nacional funcional a los intereses de los gobernantes continentales, cede el paso en favor de una descentralizada, portadora de una escala local que reconoce los intereses particulares de los isleños. Es previsible que las decisiones políticas más trascendentes para la isla, por ejemplo aquéllas ligadas a su desarrollo económico, serán mediadas en lo sucesivo por un ente, como la CDIP, de clara representatividad local.

- En la nueva institucionalidad se ha establecido una importante participación de la etnia rapanui conjuntamente con representantes chilenos. $\mathrm{La}$ creación de la CDIP pone definitivamente fin al monopolio etnochileno en la gestión isleña, especialmente evidente en los servicios públicos, y reúne a chilenos y rapanui (que pueden teóricamente simpatizar con diversas "sensibilidades" locales) en una tarea centrada en la isla y sus potencialidades.

- En virtud de la reforma a la Ley Indígena introducida por la ley 19.587 , la pertenencia a la etnia rapanui viene exclusivamente derivada del ius sanguinis, es decir, del origen rapanui de a lo menos uno de los progenitores. Se descarta la adquisición de la condición rapanui para quienes autoidentificándose como rapanui mantengan rasgos culturales de la etnia o cuyo cónyuge tenga origen rapanui. Esta disposición, que no tiene aplicación para otros pueblos indígenas del país, implica en la práctica excluir más radicalmente a los chilenos (en la especie, chilenos o chilenas casados con rapanui) en la propiedad o tenencia legal de tierras de la isla.

\section{Negociación}

El modelo de Isla de Pascua formaliza un tipo de gestión de territorio fundado más en el compromiso de intereses de los actores políticos isleños que en una proceso de planificación tecnocrática. ${ }^{13} \mathrm{La} \mathrm{com}$ posición pluricultural de la CDIP es una prueba de ello.

En primer lugar, como dijimos en otra oportunidad,

13 Sobre la planificación negociada se ha tenido presente a Hopenhayn (1989) 
la tensión chileno-rapanui parece encontrarse en un punto de equilibrio dentro del marco del modelo de administración intercultural de la isla, que acepta "rapanuizar" la isla sin poner en cuestión la soberanía chilena.

En segundo lugar, la tensión política al interior de la comunidad rapanui parece traspasarse a un nuevo escenario, la CDIP, la que por la naturaleza de sus atribuciones será la instancia llamada a dirimir las luchas familiares por el control de la tierra isleña. ${ }^{14}$ Por medio de la ley 19.587 , ya citada antes, el Consejo de Ancianos $\mathrm{N}^{\circ} 2$ obtiene, en principio, una moderación para Pascua del régimen socializado de tenencia de tierra: en el proceso de distribución de tierras, la CDIP no estará limitada a rapanui no poseedores de tierras, sino indistintamente a poseedores como no poseedores de tierras. En tanto, el Consejo de Ancianos $\mathrm{N}^{\circ} 1$ podrá invocar en el seno de la CDIP el espíritu de la Ley Indígena que, en esta materia tan decisiva, señala específicamente que en la entrega de tierra debe atenderse a criterios de necesidad de la población, puede ésta constituirse a título precario (tolerando por esta vía la reasignación de ser necesario) y en todo caso de acorde con la tradición de esta etnia.

Finalmente, las reivindicaciones de la comunidad chilena residente en la isla no han tenido acogida en las negociaciones desarrolladas hasta ahora. La moción parlamentaria de la ley 19.587 planteó originalmente la posibilidad que antiguos residentes chilenos de la isla pudieran acceder a títulos de propiedad sobre la tierra, iniciativa que finalmente no prosperó. Los chilenos residentes deberán conformarse por ahora con encontrar aliados en el seno de la CDIP.

\section{Conclusiones}

En el contexto de un país como Chile, que obsesionado por el tema de la integridad territorial ha sistemáticamente rechazado franquear a las comu-

14 En agosto de 1998, la prensa informa que las partes dieron por superado el conflicto surgido al interior de la etnia rapanui por la discusión y aplicación de la Ley Indígena. Ambos Consejos y un alto representante del gobierno de Chile suscriben un acuerdo para impulsar la CDIP. El Consejo de Ancianos $N^{\circ} 2$ se compromete a abandonar las hostilidades en tanto el Estado de Chile se obliga a pedir al Presidente de la República la parcelación del Fundo Vaitea y la desafectación de una parte del Parque Nacional para su posterior traspaso a familias rapanui. nidades indígenas derechos políticos colectivos, la experiencia pascuense debe ser apreciada en toda su magnitud. En el caso de estudio, se ha desarrollado un esfuerzo importante de mediación entre grupos con visiones de mundo antagónicas, como suele suceder en las sociedades multiculturales de origen colonial.

En la experiencia de Rapa Nui debe destacarse el cambio radical de actitud experimentado por el Estado de Chile frente a la etnia. Si durante la mayor parte del siglo XX los rapanui fueron marginados y dominados políticamente por la maquinaria política colonial, últimamente Chile ha mostrado apertura hacia la perspectiva indígena al punto de estar comprometido en la actualidad en un modelo de gestión participativo completamente inédito para el país.

La primera característica del proceso en estudio es su plena incorporación a la Ley Indígena, contando para ello, luego de la reforma legal de la ley 19.587, del apoyo de la enorme mayoría del pueblo rapanui. El reconocimiento legal de la participación del pueblo rapanui en la gestión del territorio insular y el nuevo régimen legal de las tierras confiere a los habitantes originarios un principio de equidad que les permite tratar una agenda política con el Estado de Chile. Esta agenda común, en el caso de Isla de Pascua, no fue obstáculo para que los grupos indígenas buscaran estratégicamente acumular fuerzas recurriendo a vías diversas y complementarias a la negociación, particularmente la agitación política o el desarrollo de alianzas indígenas nacionales o internacionales.

La política intercultural actual de la isla, tal cual se ha organizado en el seno de la CDIP, gira cada vez más en función del compromiso de intereses de los actores políticos. Esta es justamente la segunda característica del proceso. Estado de Chile, pueblo rapanui y sus Consejos de Ancianos, chilenos residentes en la isla, los actores se han abocado a una negociación política permanente que les ha permitido encontrar, como hemos visto, espacios de colaboración a pesar de las divergencias de intereses.

En fin, el nuevo modelo parece poner definitivamente fin a la gestión centralizada, autoritaria y etnochilena de la isla y avanzar decididamente hacia una "rapanuización" del territorio insular, en un doble sentido: por una parte, hacia una cada vez 
mayor injerencia rapanui en la política de Isla de Pascua; y, por la otra, hacia la localización de la gestión atribuyendo a la CDIP importantes facultades políticas que deberán conciliarse con las propias de la municipalidad local. Es de esperar que la actitud chilena no se altere, que se profundice la política descentralizada de la isla, y que se continúe promoviendo la recuperación de la isla para sus habitantes originarios.

\section{BIBLIOGRAFIA}

ANDUEZA, P., 2000. Mediación en una sociedad multicultural: El modelo de cogestión en Rapa Nui. En ¿Hay patria que defender? La identidad nacional frente a la globalización, Ced, pp. 233-250.

BARRIENTOS, N., 2000. Políticas públicas e identidades étnicas: La Corporación Nacional de Desarrollo Indígena. En ¿Hay patria que defender? La identidad nacional frente a la globalización, Ced, pp. 276-286.

BOURDIEU, P., 1991. El sentido práctico. Taurus Humanidades, España.

CASTRO, N., 1996. Misioneros y milenaristas: Isla de Pascua, 1864-1914. Tesis para optar al grado de Licenciado en Historia, Universidad de Valparaíso.

CONSEJO DE ANCIANOS Y GRUPOS DE ESTUDIOS AGROREGIONALES, 1990. Conclusiones preliminares del Congreso para el desarrollo de Isla de Pascua, realizado en Hanga Roa. Reunión realizada bajo los auspicios del Consejo de Ancianos y el Grupo de Estudios Agro-regionales (GEA/UAHC).

GRIFFEROS, A., 1997. La otra cara del paraíso. Comunidad, tradición y colonialismo en Rapanui 1864-1964. Tesis para optar al grado de Licenciado en Historia, Universidad de Valparaíso, Chile.
-_ 1997a. Colonialism and Rapanui identity. En Easter Island in Pacific Context. South Seas Symposium. Proceedings of the Fourth International Conference on Easter Island and East Polynesian, Stevenson, C. y otros (Eds.), pp. 365-367, University of New Mexico.

HOPENHAYN, M., 1989. Repensando la planificación en un mar de racionalidades, Ilpes, Santiago.

McCALL, G., 1996. El pasado en el presente de Rapanui (Isla de Pascua). Etnografía. Sociedades indígenas contemporáneas y su ideología, J. Hidaldo et al (Eds.) pp. 17-46. Editorial Andrés Bello, Santiago.

--- 1998. Rapanui, tradición y sobrevivencia en Isla de Pasсиа, Easter Island Foundation.

METRAUX, A., 1971. Ethnology of Easter Island. Bishop Museum Press, Honolulu. Ministerio Secretaría General de la Presidencia, 1997, Bases para un proyecto trienal de desarrollo indígena, versión 11 de abril, Chile.

PORTEOUS, J. D., 1993. The Modernization of Rapanui, Easter Island Studies: Contributions to the History of Rapanui in Memory of William T. Mulloy, S.R. Fisher (Ed). pp. 225228.

ROCHNA, S., 1996. La propiedad de la tierra en Isla de Pascua, CONADI 